\title{
Discussion on Long-Life Security Strategies for Railway Track Engineering
}

\author{
Wang Ping ${ }^{1,2}$, Chen Rong ${ }^{1,2}$, An Boyang ${ }^{1,2}$ \\ 1. Key Laboratory of High-speed Railway Engineering, Ministry of Education, Chengdu 610031, China \\ 2. School of Civil Engineering, Southwest Jiaotong University, Chengdu 610031, China
}

\begin{abstract}
Although there has been significant progress in the development of rail transportation infrastructure in China, there still exist several complicated problems regarding operational safety management and efficient maintenance, especially concerning insufficient service life. Therefore, it is particularly imperative to organize and implement a long-life security plan for railway track engineering. This paper first reviews recent achievements in the field of railway track engineering in China and then introduces developed countries' advancements in this field. Compared to developed countries, there is considerable room for improvement in current research into long-life safety in railway track engineering in China; there is an absence of top-level design, lack of systematic research work, and insufficient depth and breadth of research. This paper concludes by providing suggestions in terms of theoretical research, talent cultivation, intelligent information management, and performance improvement and recovery.
\end{abstract}

Keywords: railway track engineering; long life; security assurance; Shift2Rail

Railway is an essential part of modern transportation, undertaking approximately $1 / 3$ of the passenger traffic volume and more than $1 / 2$ of the freight traffic volume in China. Being a major component for the railway system, the track engineering construction ensures its safe service and extends its service life. It is also of great strategic significance in supporting the continuous development of the economic construction, keeping people's lives stable and orderly and maintaining the security and stability of the country and society. Therefore, a major research project for developing the security assurance strategy of railway track structures concerning the national security, national defense security and national economy, and people's livelihoods was established by the Chinese Academy of Engineering in the "Strategic Studies on Safety of Major Structures of Transportation Infrastructure" in 2015, guiding the strategic disciplinary and technological development and regulation construction in this field.

\section{Challenges of long-life security assurance of track engineering constructions in China}

After several years of development, China's fundamental network layout of track transportation has been completed preliminarily. The assurance ability has been significantly improved by basic completion of the inter-regional fast channel between the central and western regions, the gradual establishment of the high-speed railway network, and the continuous development of the inter-city railways and rail transit. At present, the operating mileage in China has reached up to approximately $1.25 \times 10^{5} \mathrm{~km}$, including over $2.2 \times 10^{4} \mathrm{~km}$ of high-speed railway. Relying on the independent innovation of heavy haul technology, China has become one of the few countries utilizing the $30000 \mathrm{t}$ heavy railway haul technology and is leading in transport efficiency. The rail transit of 27 cities has been put into operation, and the total length of the operating line has reached up to over $3000 \mathrm{~km}$.

Received date: November 17, 2017; Revised date: November 29, 2017

Corresponding author: Wang Ping, Southwest Jiaotong University, Professor. Major research field is track structure and track dynamics of high-speed and heavyhaul railway. E-mail: wping@home.swjtu.edu.cn

Funding program: CAE Advisory Project "Strategic Studies on Safety of Major Structures of Transportation Infrastructure" (2015-XZ-28)

Chinese version: Strategic Study of CAE 2017, 19 (6): 066-071

Cited item: Wang Ping et al. Discussion on Long-Life Security Strategies for Railway Track Engineering. Strategic Study of CAE, https://doi.org/10.15302/ J-SSCAE-2017.06.010 
After the Medium \& Long-term Railway Network Plan (20162030) is issued, a high-speed railway network will be established by using the "eight vertical and eight horizontal" main channel as the framework and the regional connection lines and intercity railways as the branch lines for realizing connection among high-speed provincial-level cities and efficient and convenient connection among regions. The development of railways in China has generally been rapid and outstanding; however, basic theories and technical studies on safe operation management and efficient maintenance of track engineering constructions are still inadequate [1]. The reasonable maintenance for realizing longterm safe operation and stable service of railway tracks has become an increasingly crucial problem.

Since the first railway line was built over 190 years ago, "speed" improvement has always been the intent. However, "safety" is an eternal theme of railway transportation and the core requirement and final purpose for design, construction, operation, and maintenance of railways. The occurrence of safety misadventure in a railway line will cause severe casualties, property losses, and turmoil, and such massive track engineering constructions will be subject to inevitable deterioration under complicated service conditions. In addition, possible natural disasters (e.g., earthquake, landslide, mud-rock flow, windstorm, ice, snow, and coagulation) (Fig. 1) and man-made disasters (e.g., possible local war, terrorist attack, and arson) can also cause poor performance and shorten service life of tracks. Though natural disasters and accidents can severely damage tracks, the systematic study on long-life security assurance of track structures is still in its early stage.

The transportation in China is rapidly developing, with several major engineering constructions with novel structures, complicated technology, design and execution, and high technological content being completed successively. In addition, the continuous extension of the service life of existing infrastructure and rapidly occurring damages and diseases, disaster forms, disaster-inducing behaviors and consequences have become more variable, and therefore, new contents, forms, and characteristics feature the long-life security assurance of the traffic infrastructure [3]. On one hand, because of factors such as natural deterioration, severe service conditions, and inadequate maintenance, some structures have been subject to low security, reduced durability, and poor serviceability, significantly shortening the expected service life of structures. On the other hand, with the passage of time, several engineering constructions in China are subject to gradual aging, with the designed service lives reaching successively for some major structures. Therefore, reasonable extension or use will be an important issue. In the meantime, disadvantages caused by previous high-speed and highstrength constructions will be found during maintenance within a certain period of time in the future, increasing the maintenance cost and severely influencing the transportation and social life.

Though several generations of researchers have intended to realize the continuous improvement of the high-speed railway technology since the first high-speed Shinkansen line opened in Tokaido, Japan, in 1964, problems concerning safe operation of high-speed trains are still not identified and solved completely. Problems and even accidents affecting the safe operation of highspeed railway still happen sometimes in Germany, Japan, Korea, and China because of inadequate understanding of the failure mechanism of new materials and the derailment of trains that are operated under extreme conditions. Further, there is little information available about the evolution mechanism of the dynamic properties of track infrastructure, for example, the initial defect evolution and dynamic property deterioration of high-speed railway infrastructure and the influence of troubles caused by special conditions on the safe operation of trains. For the high-speed railway infrastructure consisting of rail, fastener system, track slabs, and subgrade or bridges, the spatio-temporal evolution mechanism and law of the dynamic properties become excessively complicated because of the diversity of materials, complexity of operating conditions, spatial effect of structural distribution, time effect of service, alternate coupling effect of different sites and factors, and so on. This is one of the main obstacles to improving the safe operation technology of high-speed railways and the international problem for the development of the highspeed railway technology today. In the next 5-10 years, with the continuous construction of high-speed railway in China, a high-speed railway operating security system with high security,
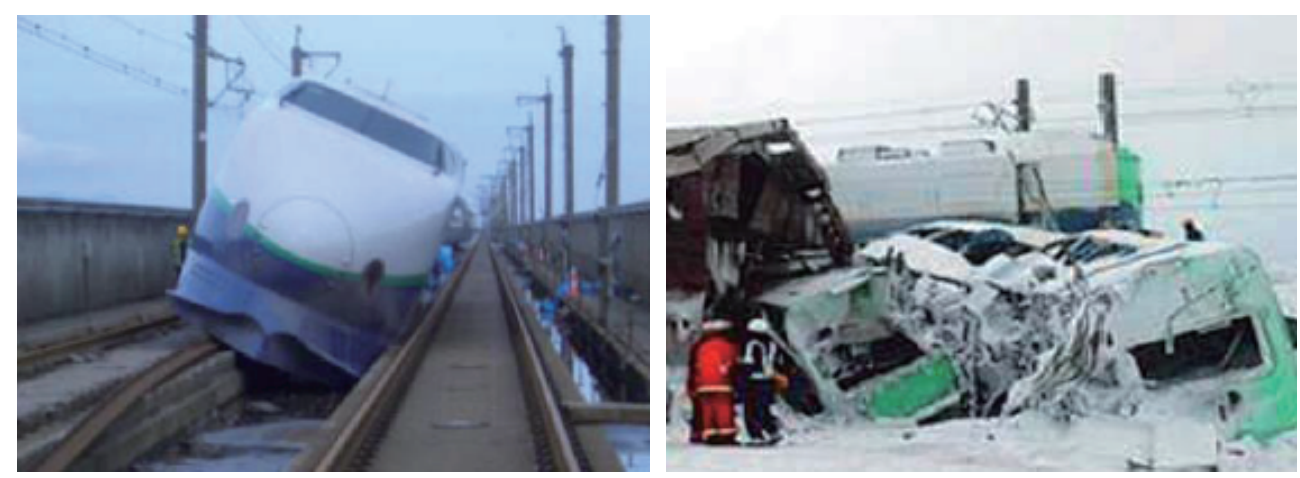

Fig. 1. Derailment of high-speed Shinkansen trains caused by earthquake (left) and snowstorm (right) [2]. 
high reliability, and high quality will soon be established. Moreover, the basic theory studies, key technologies, and processes (Fig. 2) will be crucial to the high-speed railway operating security system in China, which will also be the only way for China to study, maintain, and lead the development of the high-speed railway technology in the world.

High-speed railway is one of the biggest application platforms of advanced and new technologies. Compared to other industries, the development of high-speed railways has a significant impact on the promotion of technology, radiation of social economy and culture industries, and assurance of national security and geopolitics. In China, the development of high-speed railway has boosted the establishment of a huge industrial chain, expedited the improvement and industrialization of advanced and new technologies concerning information, materials, energy sources, and manufacture, and promoted the rapid development of industries such as agriculture, manufacture, building, energy, tourism, and logistics. At present, in China, the high-speed railway system technology has taken the leading position in the world by combining technologies with independent intellectual property rights and state-of-the-art levels, and thus further independently improving the high-speed railway technology through continuous independent innovation for taking the first place in the world and leading the development [5]. Hence, fully utilizing the relative advantages of the high-speed railway technology of China, deeply strengthening the basic theory study on the highspeed railway technology and key technology development, and taking the leading position in the high-speed railway technology can not only promote rapid development of technologies in China but also create a considerable influence on strengthening the national competitive edge and establishing a new international political and economic order.
As the natural and geological conditions of China are diverse, the solution of several complicated problems is crucial for safely operating high-speed railways [6,7]. The current systematic study on long-life security assurance of track engineering constructions is still in its early stage. It is thus crucial for administrative departments to maintain the value and functions of railway tracks effectively and realize the best properties based on the limited fund. The existing designs do not particularly pay attention to reasonable long life of structures, and the related design theories and building methods are immature. Construction and design defects influence the security of several existing structures in service, and inadequate maintenance or systematicness of existing structures may severely shorten service life of structures. Further, disaster may cause structural damages to an extent, influencing the long-term properties. No indispensable theoretical basis for evaluating the remained service life of existing structures has been presented, and there is no feasibility theory and methods for evaluating the safe service of track structures reaching the designed service life. The existing testing and monitoring technologies are inadequate for long-life safe operation of structures as the systematic study on long life is inadequate and unavailable for managing and maintaining existing structures, which is a challenge for the design of new structures.

\section{Developed countries' concern about the technology and industrial development regarding the long-life security of railway track engineering constructions}

Considering the increasingly severe situation and the important role of traffic infrastructure for the national economy and people's livelihoods, several countries have presented strategic

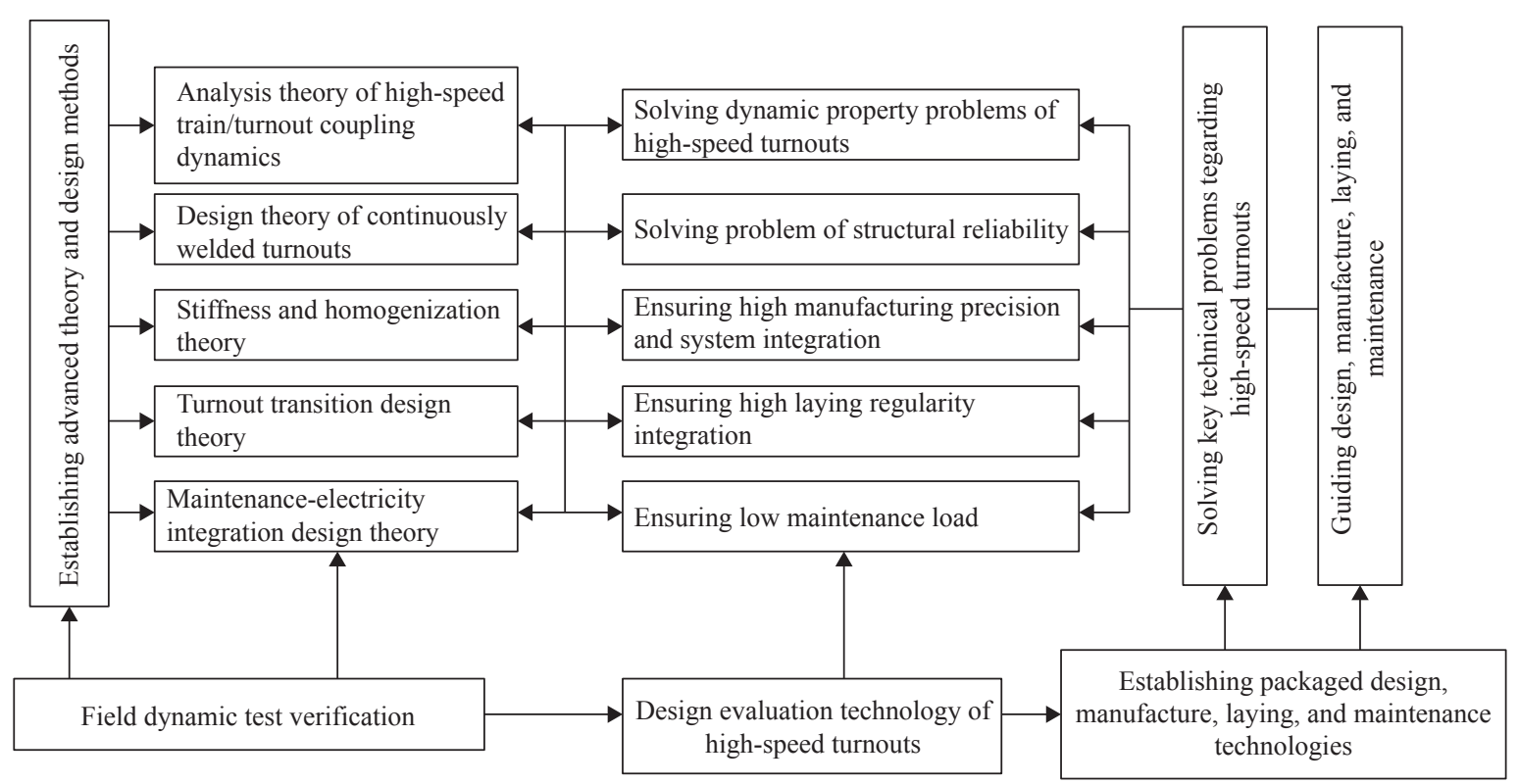

Fig. 2. Overall technological route for design of high-speed turnouts [4]. 
study plans regarding the maintenance management and security assurance of track engineering constructions, such as developing the EcoTrack system [8] of the International Union of Rail ways (UIC) and the Shift2Rail strategy [9-11] of the European Commission.

Railways are constructed and maintained at high costs, and thus account for a significant part of the infrastructure. Reduction of any such cost will influence the overall management of infrastructure. Therefore, for the management of railway lines, it is important for the railways to be maintained at the lowest suitable cost and expected quality within the needed period of time. In the 1990s, the railway departments of 24 European countries participated in the development of the EcoTrack system originated by UIC. The EcoTrack system can be used to help railway operation policy makers in effectively providing maintenance plans, adopting financial arrangements, and determining the corresponding maintenance measures. Developing the EcoTrack system is generally for solving the most complicated aspect regarding the track management operation and making decisions on track maintenance and replacement. Therefore, it is vital to solve the complicated correlations between the practical conditions (annual gross traffic tonnage, axle load, and speed), geometrical positions, and material states of tracks and the effects of track maintenance or replacement and make corresponding plans. These correlations are called "rules," part of which represents the deterioration process, and the other part represents the remediation effect after the tracks are maintained or replaced. The final part represents the empirical rules established based on the track maintenance and replacement experience of all European railway corporations in recent decades. These "rules" represent the core of the EcoTrack reasoning tool or the knowledge base. During the development of the EcoTrack system, the railway departments of the 24 European countries mentioned above compiled approximately 173 rules based on their experiences, of which 54 rules were adopted after considerable selection and listed in the EcoTrack knowledge base as the standard rules. However, all these rules can be abandoned, adopted, modified, or superimposed to make the EcoTrack system suitable for the policies of railway departments of any specified country.

In the 21 st century, the European Union (EU) realized that the European railway departments are facing a series of important challenges that obstruct the development of railway transportation modes and hamper the maintenance and strengthening of the leading position of the European railway manufacture in the global market. To strengthen the inherent advantages in environmental protection, land utilization, energy consumption, and security, the European Commission proposed a Shift2Rail strategy in 2014, which is organized and implemented by the enterprise alliance of eight representatives from the EU and the railway industry (including the railway equipment manufacturer of Alsthom, Ansaldo, Bombardier, the railway vehicle manufacturer of CAF from Spain, Siemens, Thales, and two infrastructure
operators-Network Rail and Trafikverket). A fund of 77 billion EUR will be invested before 2020 to promote the railway study and innovation through comprehensive coordination and to solve various railway problems according to the demands of railway suppliers and users. In the past, maintaining and improving the systematic security was considered necessary for railway study and innovation, and Shift2Rail's key target was providing the best security. Implementing Shift2Rail should be helpful for improving the security through technological excitation. When innovation is available for improving the security and the security rules are required to be reviewed, Shift2Rail can be used to solve those security and risk issues. Apart from being used for improving the security through technological development, Shift2Rail can also be utilized for studying and reviewing factors such as elasticity, human being, organization, and risk acceptance standards.

Compared to developed countries, further studies on long life of track engineering constructions in China are still needed because of insufficient top-level designs and inadequate systematicness, depth, and scope of research works. As railways in China have the longest operating mileage, highest expected speed, most complicated climatic and geologic conditions, and the strictest operating stability, establishing the technologies for realizing and maintaining long-life security assurance of track engineering constructions becomes more complicated than that of any other country, and thus, it is especially important to implement a longlife security assurance plan of track engineering constructions.

\section{Suggestion on implementation of a long-life security assurance plan of track engineering constructions}

\subsection{Overall target}

The traffic infrastructure will be subject to three major projects, namely, long-term maintenance, property improvement, and failure recovery under governmental guidance and resource integration, to realize breakthrough of key generic technologies that constrain the development of the traffic infrastructure and improve the overall competitiveness of the transportation in China. In 2025, it is expected that the state of major traffic infrastructure constructions will be completely determined, and a uniform information management platform of visualized, informationized, and intelligentized major traffic infrastructure constructions will be established. Major engineering constructions will be predictable, controllable, maintainable, replaceable, and rearrangeable to realize long-life security assurance under normal conditions, natural disasters, and emergencies. The development and industrialization of equipment such as modern sensors and intelligent maintainers for large-sized engineering constructions will be promoted to ensure complete self-support of core basic parts and key basic materials. New materials, structures, 
and processes concerning long-life security assurance of major structures will be used and the application range will reach $30 \%$ of the total major engineering constructions. More advanced products for the industry will be promoted for establishing transnational corporations and industrial clusters with high international competitive capacities. In 2035, the maintenance strategy and technological system of modern traffic infrastructure will be established to accomplish the normalization of long-life security assurance of major traffic infrastructure constructions and popularize the use of modern sensors, intelligent robots, and non-destructive test technology. Meanwhile, the high-level and efficient inspection, monitoring, evaluation, maintenance, or reinforcement of major structures will be conducted according to the modern information technology. The development of traffic infrastructure will become a new theme for the technological innovation in China, with the main field possessing leading abilities and obvious competitive advantages in innovation to achieve the strategic target of great transportation power.

\subsection{Strategic mission}

(1) Considering problems such as immature basic theory and method with regard to long-life security assurance, it is pertinent for the innovation ability of the track engineering industry to be improved. The development of key core technologies should be supported by the National Science \& Technology Program (specialized techniques and funds, etc.), and the achievement transformation should be promoted. Demonstration projects concerning key fields such as high-speed tracks, heavy haul tracks, and rail transit should be promoted, and advanced design technologies characterized by green, intelligence, and coordination should be popularized.

(2) Training plans concerning long-life security assurance of track engineering constructions should be provided for professionals and outstanding engineers to cultivate high level of quality and urgently needed innovative talents. Training centers for engineering construction properties and security assurance should be established to form high-level professional teams. Elite professionals should be selected through various methods and should be trained abroad. International training bases should be planned and built, and a talent incentive mechanism should be established to commend and encourage professionals. The talent demand prediction should be strengthened and the information bases for various talents perfected to prepare the talent evaluation system and establish information issuance platforms

(3) For different types of major traffic infrastructure constructions under normal operating conditions, a uniform service information management platform of visualized, informationized, and intelligentized should be established. A full-service life information achievement regarding design, construction, operation, damage, and aging should be established based on the modern information technologies of "Internet Plus", Internet of Things, big data, and cloud computing to support the technical development of structural safety, design review, maintenance, and inspection. The long-term service properties of major structures should be maintained, and the local or global long-term properties and development of major structures should be grasped effectively during the service life to retain good properties.

(4) For major engineering constructions whose designed service life is approaching the deadline or is being shortened, the properties should be subject to new material, new structure, and new process, and the carrying capacity of the structures should be strengthened and the service life of large-sized structures extended. It is also important to focus on the development of special metal function materials, functional macromolecule, and advanced composite materials and promote the key technologies and equipment for studying the preparation of new materials. Advanced applicable technologies should be adopted by enterprises, and the product structures should be optimized. The design, manufacturing process, and management levels should be improved considerably to promote the optimization of the infrastructure.

(5) For local damages of major traffic infrastructure constructions caused by natural disasters or accidents, a management system for emergency maintenance and expeditious building of large-sized structures as well as equipment development and emergency rescue should be established. The failure of or property recovery plans of major traffic infrastructure constructions should also be implemented. A new industry dealing with maintenance and reinforcement of major traffic infrastructure constructions should be established based on modes of modernized operation management, full-life prevention and maintenance, and development of intelligentized automatized maintenance equipment.

\section{Conclusions}

There are immense existing track engineering constructions in China that are also developed rapidly, thus creating severe challenges in long-life security assurance of structures. Compared to developed countries, there is need for further studies on long life of track engineering constructions in China. Moreover, few strategic study plans on maintenance management and security assurance of track engineering constructions are presented. Developing technologies for creating and maintaining long-life security assurance of track engineering constructions in China is more complicated than in any other country as, in China, the operating mileage is the longest, the expected speed is the highest, the climatic and geologic conditions are the most complicated, and the operating stability is the strictest. To ensure the operating security of railway tracks and extend service life, China's comprehensive ability in the long-life security assurance (design, construction, and management) of railway track engineering constructions can be promoted to achieve the leading position in 
the world by improving innovation ability, strengthening talent cultivation, and establishing a new industrial system dealing with the construction and maintenance of track engineering constructions. Therefore, it is suggested that the long-life security assurance plan of track engineering constructions be implemented as soon as possible.

\section{References}

[1] Xu Y D, Gao B S, Yang J Z et.al. Analysis of the "going global" strategy of China railway engineering construction technical standards [J]. Journal of Railway Engineering Society, 2016, 33(5): 116-122. Chinese.

[2] Jin X S, Guo J, Xiao X B et.al. Key scientific problems in the study on running safety of high speed trains $[\mathrm{J}]$. Engineering Mechanics, 2009(26): 8-22. Chinese.

[3] Zhai W M, Zhao C Y, Xia H et.al. Basic scientific issues on dynamic performance evolution of the high-speed railway infrastructure and its service safety [J]. Scientia Sinica Technologica, 2014, 44(7): 645-660. Chinese.

[4] Wang P, Chen R, Xu J M et.al. Theories and engineering practices of high-speed railway turnout system: survey and review [J].
Journal of Southwest Jiaotong University, 2016, 51(2): 357-372. Chinese.

[5] Lu C F. Highlights of China high speed railway [J]. Science \& Technology Review, 2015, 33(18): 13-19. Chinese.

[6] Zhao G T. Study on management standard of frost heaving of ballastless track subgrade on high-speed railway in service cold regions [J]. Journal of the China Railway Society, 2016, 38(3): 1-8. Chinese.

[7] Du Y L, Zhang Y Z, Zhao W G. Construction of the high-speed railway line engineering safety monitoring system $[\mathrm{J}]$. China Civil Engineering Journal, 2012(45): 59-63. Chinese.

[8] Rivier R E. ECOTRACK: A tool for track maintenance and renewal managers [J]. WIT Transactions on The Built Environment, 1998(37): 733-742

[9] Haltuf M. Shift2Rail JU from Member State's Point of View [J]. Transportation Research Procedia, 2016(14): 1819-1828.

[10] Gogos S, Letellier X. IT2Rail: Information Technologies for Shift to Rail [J]. Transportation Research Procedia, 2016(14): 32183227.

[11] Peris E, Goikoetxea J. Roll2Rail: New Dependable Rolling Stock for a More Sustainable, Intelligent and Comfortable Rail Transport in Europe [J]. Transportation Research Procedia, 2016(14): $567-574$. 